\title{
Fifty-six years of plastic surgery
}

\author{
Thomas M. Biggs \\ Baylor College of Medicine, Houston, TX 77007, USA. \\ Address for correspondence: Prof. Thomas M. Biggs, 50 West Terrace, Houston, TX 77007, USA. E-mail: tbiggsmd2@aol.com
}

Evolution is the natural state of all things and certainly our field of plastic surgery is not exempt. The appearance on the scene of a new journal dedicated to the pursuit of excellence is no exception. It is my distinct pleasure to become the Editor-in-Chief of Plastic and Aesthetic Research and to help guide it into the evolutionary process so it can play its role in the advancement of methods to make people's lives better.

Plastic surgery is an exceptional field. It is not regionally-based or system-based. It is not cardiovascular surgery; it is not genitourinary surgery; it is not ear, nose, and throatsurgery. Then what is it?

We know in ancient India forehead flaps were being used to reconstruct noses, which had been amputated as punishment for adultery. This was surgery necessitating familiarity with random flaps. Therefore, it is reasonable to assume that random flaps were probably being employed in other reconstructive problems; however, we have no credible proof of this. We do have proof of skin grafts, rhinoplasties, face lifts and a variety of other aesthetic and reconstructive procedures being done in 19th century Europe, but not by surgeons who were organized and worked collectively to promote the spread of common knowledge. This did not occur until the advent of World War I.

During World War I, medicine advanced. Individual military personnel with injuries of massive degree, which heretofore had been fatal, were being saved. However, resulting traumatic sequelae were well-beyond the knowledge of contemporary treatment modalities.

\begin{tabular}{|l|l|}
\hline \multicolumn{2}{|c|}{ Access this article online } \\
\hline Quick Response Code: & Website: \\
\hline & www.parjournal.net \\
\cline { 2 - 2 } & \\
\hline & \\
\hline
\end{tabular}

To deal with these problems the allied forces organized a unit under the direction of Sir Harold Gillies (in private life an otolaryngologist) and surgeons working in this unit were treating many of the problems previously deemed irreparable. After the war, the body of knowledge and experiences achieved from these efforts were disseminated to all parts of the world giving birth to organizations of like-minded surgical adventurers who called themselves "plastic surgeons"... from the Greek word "plastikos" or to form, mold, or make new. It was impossible to limit themselves to one system or to one region. The description that best identified their specialty was innovation... and that is what we plastic surgeons are... innovational surgeons.

The evolutionary process moved rapidly after World War I and even more rapidly during World War II and the years succeeding it. My personal observation of the process began during my residency in 1958. We were doing cleft lips by the Tennison technique as Ralph Millard had not yet become well-known. The full understanding of fluid and electrolyte physiology in burn patients, as well as today's commonly known knowledge of burn wound care, had not come on the scene. The rare face lift was a simple skin stretch technique as Mitz and Peyronie were still in training and the superficial musculoaponeurotic system was unrecognized. The open rhinoplasty was reserved for nasal reconstruction with cleft lip. Open aesthetic rhinoplasty was generally unheard or were mere fantasies. IIIous and liposuction were decades away as was Uebel and Barrera's single follicle method of hair restoration.

The list of operative evolution goes on and on; but, plastic surgery advanced in other skills as well as in techniques. Our anesthesia was ether, with cyclopropane coming in a bit later; but, both of these were explosive; therefore, ruling out use of an electro-cautery. It was all clamp and tie for hemostasis (a big problem as we were not aware of aspirin's effect on coagulation) or local. The only sedation we had with local was an assortment of barbiturates. 
Lighting for surgery was one overhead light, then a movable light stand... and the endoscope was unheard of ("take a deep breath" became my mantra).

Management of postoperative pain in the early years now seems near barbaric and penicillin (a Godsend) had just become well-known.

Current evolutionary excitement seems focused on the use of fat. Whereas Guerro Santos and Chachir were extolling the miracle of fat grafting before the turn of the century, it was not until Coleman described the importance of the fat's being grafted in very small droplets that most plastic surgeons took an interest in fat grafting. Then, with Khouri's introduction of the BRAVA system, large volume fat grafting became a reality. Now, the woman wishing breast augmentation without a foreign material put into her body can be accommodated. Now, immediate breast reconstruction can be carried out with no expander, no silicone implant, and no distal flap, with a sensitive breast the usual expectation.

Yes, the evolution in plastic surgery has been remarkable... change, change, change... constant and unremitting... but one thing has not changed: our sole purpose in all our efforts remains the same. Our identity as plastic surgeons... as innovational surgeons... implies that we use special techniques as surgeons to fulfill our single and primary goal... to make our patients' lives longer, better, or both. To this we remain dedicated... and with this new journal we hope the make the path straighter and more direct for all our colleagues.

How to cite this article: Biggs TM. Fifty-six years of plastic surgery. Plast Aesthet Res 2014;1:1-2.

Source of Support: Nil, Conflict of Interest: None declared.

Received: 06-05-2014; Accepted: 13-05-2014 